\title{
Editorial
}

\section{News in Antimicrobial Resistance: Documenting the Progress of Pathogens}

\author{
Allison McGeer, MD
}

Knowing is not enough; we must apply.

Willing is not enough; we must do.-Goethe

Antimicrobial resistance is expensive and deadly, and consumes an increasing proportion of infection control practitioners' time. In 2003, four of 12 issues of Infection Control and Hospital Epidemiology were almost entirely devoted to questions surrounding antibiotic resistance and all but one of the issues of the Journal of Hospital Infection contained articles about the problem. As reflected in this month's issue of Infection Control and Hospital Epidemiology,,${ }^{1-5}$ most attention is being paid to resistance in the two gram-positive pathogens that are the most common cause of hospital-acquired infections-Staphylococcus aureus and enterococci. However, we can expect to see increasing numbers of publications documenting the emergence of clinically significant resistance in the two other common nosocomial pathogens-Escherichia coli and Klebsiella species.

Articles in this issue of Infection Control and Hospital Epidemiology document two important new problems with antimicrobial resistance. Warren et al. and Harris et al. provide quantitation of the strong associations between colonization with methicillin-resistant $S$. aureus (MRSA) and vancomycin-resistant enterococci (VRE), and VRE and extended-spectrum beta-lactamase-producing $E$. coli and Klebsiella. They note that risk factors for acquiring antibiotic-resistant organisms, including severity of underlying illness, duration of hospital stay, colonization pressure, and antimicrobial use, are common for all antibiotic-resistant pathogens. Our most vulnerable patients are most likely to be infected with resistant pathogens, and most likely to suffer in consequence. In addition, as noted by Warren et al., co-colonization with MRSA and VRE indubitably increases the risk of the emergence of vancomycin-resistant $S$. aureus. To date, this has rarely occurred. ${ }^{6}$ However, the continuing increase in MRSA and VRE co-colonization will inevitably lead to further episodes of transfer.

It is clear that the increasing prevalence of MRSA and VRE in healthcare institutions is primarily related to transmission of strains from patient to patient, with antibiotic pressure providing an important facilitative role. ${ }^{7}$ In contrast, antibiotic resistance in E. coli and Klebsiella species has often been viewed as a result of the overuse of antibiotics, rather than a consequence of the transmission of strains (or plasmids) within hospitals. The documentation by Harris et al. of the very high association between colonization with VRE and extended-spectrum beta-lactamase-producing bacteria suggests that transmission may be a greater problem than is commonly thought. Recently, a careful examination of the issue by Paterson et al. ${ }^{8}$ arrived at the conclusion that patient-to-patient transmission in the hospital is critically important in the emergence of antibiotic resistance in Klebsiella species.

Warren et al., Eveillard et al., and Leman et al. document another problem with hospital-derived antimicrobialresistant organisms - not only are they often transferred to long-term-care facilities, they may also cause problems in the community. Warren et al. noted that patients co-colonized with MRSA and VRE were more likely to be transferred to long-term-care facilities than were other patients. Eveillard et al., in a carefully designed study of employees in a hospital in France with endemic MRSA, documented not only infections in healthcare workers, but also substantial MRSA transmission in the households of colonized healthcare workers. Leman et al. found that $2.1 \%$ of an American Indian population was colonized with MRSA. Forty-four percent of the MRSA colonization occurred in individuals with healthcare risk factors. The recent emergence of true community-acquired MRSA in many parts of the world may make control of MRSA in hospitals more challenging. However, in most cases, what appears to be community-acquired MRSA is often actually healthcare-acquired MRSA. ${ }^{9}$

The article by Leman et al. provides another important insight into the problem of MRSA control. During an outbreak of community-onset MRSA infections in an American Indian community in which $34 \%$ of all $S$. aureus 
infections were due to MRSA, the study found that only $2 \%$ of the residents of the population tested were colonized by MRSA. This is an important finding because it suggests that even when MRSA infections are relatively common in the community, they may not be associated with a high prevalence of colonization. Thus, the increasing documentation of community-acquired MRSA infections should not lead us to give up trying to control MRSA in the hospital setting; it does mean that MRSA is, in fact, prevalent in the general population. In addition, it is important to remember that community-acquired strains of MRSA are very different from hospital-acquired strains. There is evidence from Canada that community-acquired strains are not well adapted to spread within hospitals, ${ }^{10}$ and healthcare-associated MRSA remains at a very low level in several Northern European countries despite the presence of community outbreaks of the mecIV type MRSA.

New problems with antimicrobial resistance can be viewed as a challenge. However, these articles illustrate the discouraging reality that the hospitals they describe are hospitals in which control programs for antimicrobial-resistant organisms have been either untried or substantially ineffective. For instance, in the intensive care unit described in the article by Warren et al., $50 \%$ of patients were colonized with VRE. In hospitals belonging to the German Nosocomial Infection Surveillance System (KISS), $23.7 \%$ of $S$. aureus infections were due to MRSA. ${ }^{3}$ These examples reflect reality throughout much of the United States. The recent report of the National Nosocomial Infections Surveillance System documented substantial continuing increases in resistance for almost every pathogen examined. ${ }^{11}$

The problems of antibiotic resistance in nosocomial S. aureus and enterococci have been reviewed in detail in the new Society for Healthcare Epidemiology of America (SHEA) guideline. ${ }^{7}$ MRSA and VRE are associated with mortality, morbidity, and substantial cost. Although the cost-effectiveness of transmission control programs continues to be debated, there is growing evidence that such programs are both effective and cost-effective. Why is it, then, that studies such as those in this issue of Infection Control and Hospital Epidemiology continue to document not only increasing rates of MRSA, VRE, and extended-spectrum beta-lactamase-containing gram-negative bacteria, but also evidence of export of these pathogens to the community? Part of it is related to the many difficulties in performing randomized, controlled trials of infection control interventions, so that we lack "gold standard" evidence to support these programs. In North America, it may also be that we don't pay as much attention as we should to new approaches and effective programs in Europe and elsewhere around the world. However, the major problem is that neither healthcare professionals nor healthcare administrators are willing to invest intelligently in prevention. Death and morbidity from hospital-acquired infection are too often regarded as unavoidable and thus acceptable, and prevention programs are seen as costly and relatively unimportant.

In this regard, the renewed interest in infection control of the Joint Commission on Accreditation of Healthcare
Organizations (JCAHO) is to be applauded. JCAHO and infection control professionals will need to work hard to make sure that there is adequate funding for the new mandate, and that infection control programs make the most of the new standards. One outcome of improved infection control programs that can be relatively easily measured is the reduction in transmission of antimicrobial-resistant pathogens. Antimicrobial resistance is also a widely recognized concern, facilitating communication with senior administrators and boards. If each infection control practitioner could persuade his or her administration to make control of antimicrobial-resistant organisms a primary goal and worked hard to implement measures that have worked, ${ }^{7,12-14}$ we would start to make substantial inroads into the problem of transmission of antimicrobial resistance and the morbidity and mortality it causes. We could then look forward to reading reports of successful intervention programs instead of articles such as those in this issue of Infection Control and Hospital Epidemiology, which contain the careful documentation of the failure of infection control to control serious infections due to antimicrobial-resistant pathogens.

\section{REFERENCES}

1. Warren DK, Nitin A, Hill C, Fraser VJ, Kollef MH. Occurrence of co-colonization or co-infection with vancomycin-resistant enterococci and methicillin-resistant Staphylococcus aureus in a medical intensive care unit. Infect Control Hosp Epidemiol 2004;25:99-104.

2. Harris AD, Nemoy L, Johnson JA, et al. Co-carriage rates of vancomycinresistant Enterococcus and extended-spectrum beta-lactamase-producing bacteria among a cohort of intensive care unit patients: implications for an active surveillance program. Infect Control Hosp Epidemiol 2004;25:105-108.

3. Gastmeier P, Schwab F, Geffers C, Riuden H. To isolate or not to isolate? Analysis of data from the German Nosocomial Infection Surveillance System regarding the placement of patients with methicillin-resistant Staphylococcus aureus in private rooms in intensive care units. Infect Control Hosp Epidemiol 2004;25:109-113.

4. Eveillard M, Martin Y, Hidri N, Boussougant Y, Joly-Guillou M-L. Carriage of methicillin-resistant Staphylococcus aureus among hospital employees: prevalence, duration, and transmission to households. Infect Control Hosp Epidemiol 2004;25:114-120.

5. Leman R, Alvarado-Ramy F, Pocock S, et al. Nasal carriage of methicillinresistant Staphylococcus aureus in an American Indian population. Infect Control Hosp Epidemiol 2004;25:121-125.

6. Chang S, Sievert DM, Hageman JC, et al. Infection with vancomycinresistant Staphylococcus aureus containing the van A resistance gene. $N$ Engl J Med 2003;348:1342-1347.

7. Muto CA, Jernigan JA, Ostrowsky BE, et al. SHEA guideline for preventing nosocomial transmission of multidrug-resistant strains of Staphylococcus aureis and Enterococcus. Infect Control Hosp Epidemiol 2003;24:362-386.

8. Paterson DL, Ko W-C, Gottberg AV, et al. International prospective study of Klebsiella pneumoniae bacteremia: implications of extended-spectrum beta-lactamase production in nosocomial infections. Ann Intern Med 2004;140:26-32.

9. Tambyah PA, Habib AG, Ng TM, Goh H, Kumarasinghe G. Communityacquired methicillin-resistant Staphylococcus aureus infection in Singapore is usually "healthcare associated." Infect Control Hosp Epidemiol 2003;24:436-438.

10. Embil J, Ramotar K, Romance L, et al. Methicillin-resistant Staphylococcus aureus in tertiary care institutions on the Canadian prairies 1990-1992. Infect Control Hosp Epidemiol 1994;15:646-651.

11. National Nosocomial Infections Surveillance System report: data summary from January 1992 to June 2003, issued August 2003. Am J Infect Control 2003;31:481-498.

12. Pittet D, Hugonnet S, Harbarth S, et al. Effectiveness of a hospital-wide programme to improve compliance with hand hygiene. Lancet 2000;356:1307-1312.

13. Ostrowsky BE, Trick WE, Sohn AH, et al. Control of vancomycin-resistant enterococcus in health care facilities in a region. $N$ Engl J Med 2001;344:1427-1433.

14. Carling P, Fung T, Killion A, Terrin N, Barza M. Favorable impact of a multidisciplinary antibiotic management program conducted during 7 years. Infect Control Hosp Epidemiol 2003;24:699-706. 